\title{
Illköğretimde Program Değerlendirmenin Öğretmen Görüşleri Doğrultusunda İncelenmesi
}

\begin{tabular}{|c|c|}
\hline Makale Bilgisi & Öz \\
\hline DOI: $10.14527 / 140$ & \multirow{6}{*}{ 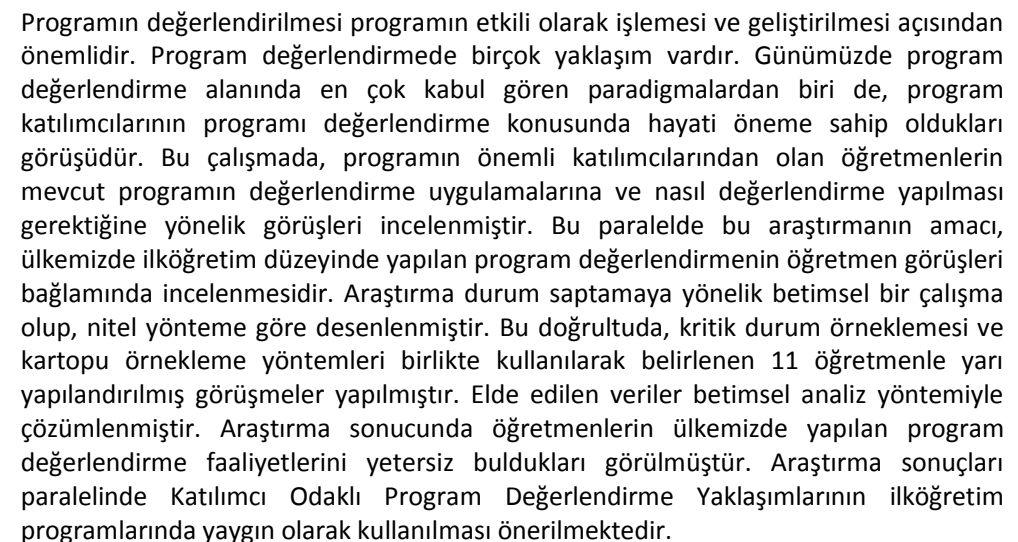 } \\
\hline Makale Geçmişi: & \\
\hline 25 Nisan 2013 & \\
\hline Düzeltme 29 Mayıs 2014 & \\
\hline Kabul $\quad 24$ Ağustos 2014 & \\
\hline $\begin{array}{l}\text { Anahtar Kelimeler: } \\
\text { Program geliştirme, } \\
\text { Program değerlendirme, } \\
\text { Katılımcı değerlendirme. }\end{array}$ & \\
\hline
\end{tabular}

\section{An Examination of Curriculum Evaluation in Elementary Schools with Regard to Teachers' Views}

\begin{tabular}{l} 
Article Info \\
\hline DOI: $10.14527 / 140$ \\
\hline Article history: \\
Received $\quad 25$ April 2014 \\
Revised $\quad 29$ May 2014 \\
Accepted $\quad 24$ August 2014 \\
\hline Keywords: \\
Curriculum development, \\
Curriculum evaluation, \\
Participant-oriented evaluation.
\end{tabular}

\begin{abstract}
The evaluation of curriculum is significant in terms of curriculum's working and being developed effectively. There are a lot of curriculum evaluation approaches. Recently, one of the most widely accepted paradigms in the field of curriculum evaluation is the opinion that the participants of curriculum are vital for curriculum evaluation. In this study, the views of teachers, who are among the important participants of the curriculum, related to the evaluation of present curriculum and how the evaluation should be carried out were analyzed. In this regard, the aim of this research is analyzing the curriculum evaluation at elementary level in relation with teachers' views. The research being a descriptive study regarding defining a case, is designed according to qualitative method. Accordingly, semi-structured interviews were conducted with determined 11 teachers using critical case sampling and snowball sampling methods. The data was analyzed with descriptive analysis method and presented being supported by direct quotations. As a result of research, it is observed that teachers find the curriculum evaluation activities in our country insufficient. In parallel with the results, the use of Participant-Oriented Evaluation Approach widely in elementary curricula is recommended.
\end{abstract}

*Yazar:memkar@cu.edu.tr 


\section{Giriş}

Öğretmen ve konu merkezli eğitim anlayışlarının yerine, günümüzde yaygın olarak öğrenci merkezli eğitim uygulamaları kabul görmektedir. Eğitimde yaşanan bu paradigma değişimi programların da revize edilmesini gerektirmiştir. Bu doğrultuda, geleneksel öğretim programları kendilerini yenileyerek, öğrenenleri merkeze alan, onların ilgi ve ihtiyaçlarına önem veren yenilikçi programlara dönüşmüşlerdir. Ülkemizde de bu dönüşüm, 2005-2006 eğitim öğretim yılında tüm okullarda uygulamaya konulan yapılandırmacılık temelli öğretim programıyla başlamışır. Biggs'e (1996: 347) göre yapılandırmacı program; eğitim programının hedeflerini amaca uygun yüksek bilişsel düzeyi gösteren edimler şeklinde ifade etmede, edimleri ortaya çıkaracağına inanılan öğrenme-öğretme etkinlikleri hakkında karar vermede, değerlendirmede ve özet olarak öğrenci edinimini raporlaştırmada öğretim tasarımının tüm aşamalarına rehberlik eden bir görüş olarak anlaşılmalıdır. Yapılandırmacı sınıf ortamlarında öğrenenin görevi; var olan bilgilerini sorgulayarak bilgilerindeki eksiklikleri gidermek için araştırmalar yapmak; eleştirel ve yaratıcı düşünme süreçleri yardımıyla sosyal ortamlar içerisinde öğrenme sürecine aktif katılmaktır. Ancak bu yaklaşımda öğrencinin öğrenme yeteneği ve başarısı kısmen öğrenciye bağlıdır (Horstman ve White, 2002).

Yapılandırmacı yaklaşımın temel düşüncelerinden biri de, öğrencilerin kendi düşüncelerini, öğretmen desteği ve yol göstermesi yardımıyla geliştirebileceğidir (Warwick ve Stephenson, 2002). Yapılandırmacı yaklaşımda öğrenmenin meydana gelmesi için öğrenme sürecindeki en önemli öğelerden biri de yönlendirici rolündeki öğretmenlerdir. Yapılandırmacı yaklaşım, öğretmenin bilgi dağıtııılık görevini bırakarak bunun yerine, eğitim programını ve öğretimsel yöntemleri sürekli olarak analiz etmesini gerektirmektedir (Kaptan ve Korkmaz, 2000). Bu nedenle yapılandırmacı yaklaşımda yönlendirici rolünü üstlenen öğretmen, önemli bir role sahiptir.

Program geliştirme en genel anlamıyla eğitim programlarının tasarlanması, uygulanması, değerlendirilmesi ve değerlendirme sonucu elde edilen veriler doğrultusunda yeniden düzenlenmesi sürecidir (Erden, 1998, s.4). Program değerlendirme ise program geliştirme sürecinin son aşamasıdır. Eğitimde değerlendirme, öğrencilerin eksikliklerini belirleme, amaçlara ne oranda ulaştıklarını tespit etme, uygulanan yöntemin etkinliğini anlama, uygulanan programın ne oranda etkili ve verimli olduğunu belirleme, yeni bir programın geliştirilmesine yönelik etkileri belirleme ve okul uygulamalarını topluma gösterme vb. gibi çeşitli amaçlarla yapılır (Doğan, 1997). Kısaca, eğitim süreçlerinde değerlendirme özel olarak öğrencilerin ne düzeyde öğrendiklerini ya da öğrenme eksikliklerini belirlemek ve bunları düzeltmek amacıyla yapııırken, daha genel biçimde ise uygulanan bir programın etkililiğini ya da başarılı olup olmadığını ortaya koyma amacına dönük olarak yapılmaktadır (Özdemir,2009).

Tyler (1949)'a göre, değerlendirme bir program çalışmasının temel fonksiyonudur ve değerlendirme süreci, bir programın hedeflerinin ve değiştirmesi beklenen davranışların tam olarak ne düzeyde gerçekleştirildiğini belirleme sürecidir. Demirel (2006), program değerlendirmenin, genelde programa dayalı eğitim kaynaklarını kabul etme, değiştirme ya da ortadan kaldırma kararının verilebileceği bilgileri içerdiğini belirtmiştir. Değerlendirme sonuçları program geliştirme uzmanlarına programa devam, gözden geçirme veya yeni bir aşamaya geçme konusunda bilgi vermektedir. Kısaca amaçlanan davranışların gerçekleşme düzeylerini saptama ve uygulama sonucunda programın aksayan yönlerini belirleme ve gerekli düzeltmeleri yapma program değerlendirme sürecini oluşturur (Yaşar, 1998).

Ülkemizde uygulanan ilköğretim programı yapılandırmacılık temellidir. Yapılandırmacı program tasarıları; öğrenenlerin ilgilerine, ön yaşantılarına ve ön bilgilerine öncelik tanımalı, daha esnek ve öğrenen görüşlerine dayalı olarak öğretmen ve öğrenenlerle birlikte hazırlanmalıdır. Program geliştirilirken öğretmenler, kendi kararlarıyla öğrenenlerin ilgileri arasında orta bir yol bulmalı; böylelikle yapılandırmacılığın süreç özellikleri açığa çıkarılmalıdır (Yurdakul, 2005, s.48). Öğretmenler, program geliştirmede ve değerlendirmede aktif role sahip katılımcılardan olmalıdır.

Eğitim programının geliştirilmesi ve değerlendirilmesi iç içe olduğundan, programın temel felsefesindeki değişim, değerlendirme sürecinin de değişimini beraberinde getirmektedir. Eğitimde değerlendirme, öğrencilerin eksikliklerini belirleme, amaçlara ne oranda ulaştıklarını tespit etme, 
uygulanan yöntemin etkililiğini anlama, uygulanan programın ne oranda etkili ve verimli olduğunu belirleme, yeni bir programın geliştirilmesine yönelik etkileri belirleme ve okul uygulamalarını topluma gösterme gibi çeşitli amaçlarla yapılır (Marsh ve Willis, 2007).

Eğitimdeki paradigma değişimleri program değerlendirme sürecinde de değişime ve geleneksel değerlendirme yaklaşımlarına alternatif olarak birçok farklı yaklaşımın ortaya çıkmasına yol açmıştır. Geleneksel değerlendirme yaklaşımlarına getirilen en büyük eleştirilerden biri, çoğu değerlendirme işleminin, değerlendirme uzmanının programın uygulandığı ortama ayak basmadan yürütülmesidir. Bu duruma tepki olarak ortaya çıkan değerlendirme yaklaşımlarından en çok dikkat çekeni ise "Katılımcı Odaklı Değerlendirme Yaklaşımı"dır. Bu yaklaşımın savunucuları, değerlendirilecek olan programın katılımcılarının değerlendirme sürecine dahil olmalarını çok önemli görürler. (Worthern, Sanders ve Fitzpatrick, 1997, ss.153-154). Katılımcılar arasında programın uygulandığı grup, destekleyiciler ve en önemli öğelerden biri olan uygulayıcı, yani öğretmenler bulunmaktadır.

Ülkemizde 2005 ilköğretim programını değerlendirmek amacıyla yapılan çalışmalar incelendiğinde; Gelen ve Beyazıt (2006), öğretmen, yönetici, müfettiş ve öğrencilerle yürüttükleri çalışmalarında, eski ve yeni programlarla ilgili görüşleri incelemiş, bir nevi 2005 ilköğretim programını değerlendirmişlerdir. Bukova, Güzel ve Alkan (2005), yeni ilköğretim programının pilot uygulamasını, Çınar, Teyfur ve Teyfur (2006), yapılandırmacı eğitim yaklaşımı ve programını, ilköğretim okulu öğretmenleri ve yöneticilerinin görüşleriyle değerlendirilmiştir. Yücel, Karaman, Batur, Başer ve Karataş (2006)'ın ve Bümen (2005)'in çalışmaları 2005 ilköğretim programının öğretmen görüşleriyle değerlendirilmesini amaçlamıştır. Görgen, Karaçelik, Kocatürk-Kapucu ve Kaya (2008) ise Illköğretim 1-5 programlarını sınıf öğretmenlerinin görüşlerine göre değerlendirmişlerdir.

Bunların yanında ders bazında yapılan çalışmalar da mevcuttur. Gömleksiz ve Bulut (2007) araştırmalarında ilköğretim Türkçe dersi öğretim programını, Arslan ve Demirel (2007), ilköğretim 5. sınıf sosyal bilgiler öğretim programını, İzci, Özden ve Tekin (2006) fen ve teknoloji öğretim programını öğretmen görüşü ve doküman analizine dayalı olarak değerlendirmişlerdir. Ayrıca, illköğretim matematik programlarının değerlendirilmesinde öğretmenlerin, okul yöneticilerinin, ilköğretim müfettişlerinin, veliler ve öğrencilerin anket veya görüşme formlarıyla görüşlerinin alındığı (Bal, 2008; Butakın ve Özgen, 2007; Halat, 2007; Orbeyi, 2007; Sarıer, 2007; Uşun ve Karagöz, 2009) çalışmalar da ilgili literatürde yer almaktadır.

Literatürde yer alan bu araştırmalar incelendiğinde, yapılan çalışmaların genellikle öğretmenlerle yürütülmüş olmalarına rağmen mevcut programın öğeleri hakkında görüş alma, öğretmen eksiklerini belirleme, hizmet içi eğitim ihtiyacını belirleme gibi amaçların ötesine geçemeyip, öğretmenlerin programa ait dönütlerinin programa ulaştırılmasına hizmet etme konusunda yetersiz kaldıkları görülmektedir.

Eğitimde değerlendirme eğitimin temel bileşenlerinden programın değerlendirilmesiyle başlar. Çünkü eğitim programları, toplumun gereksinim duyduğu insan özelliklerinin belirleyicisidir. Bir ülkenin, bir kurumun eğitim programlarına bakılarak o ülkede yetiştirilecek bireylere hangi özelliklerin kazandırılıp kazandırılamayacağı bireylerin hangi beceri ve tutumlara sahip olacağı hakkında yorumlar yapılabilir. Bu nedenle uygulanan programların aksaklık ve eksiklikleri giderilmeli, toplumdaki ve bilim alanındaki değişmelere göre yeniden düzenlenerek program sürekli değerlendirilmelidir (Yüksel ve Sağlam, 2012). Programın ne kadar etkili olduğunun sorgulanması ve değerlendirilmesi sürekli gelişim için başlangıç noktasıdır(Gözütok, 2001). Ancak, program değerlendirme ülkemizde oldukça zayıf kalmaktadır.

Yapılan çalışmalar incelendiğinde alınan sonuçların ya tek bir ölçüte dayalı ya da oldukça sınırlı bulgular üzerinde oluşturulmuş yeni yöntemlerin değerlendirmesi olduğu görülmektedir (Yaşar, Gültekin, Köse, Girmen ve Anagün, 2005). Ülkemizde MEB tarafından programların denenmesi aşamasında yapılan değerlendirme çalışmalarının dışında, 2005-2006 yılından bu yana uygulanan ilköğretim programlarının kapsamlı ve sistematik biçimde değerlendirilmesine yönelik program değerlendirme çalışmalarının yapılmadığı gözlenmiştir (Özdemir, 2009).Türkiye'de yapılan program değerlendirme çalışmalarına ilişkin Yaşar vd. (2005) tarafından yapılan araştırmada; çalışmaların 
genellikle programın bir boyutuna odaklanıldığı, çoğunun nicel yöntemlerle ve yalnızca anketlerle yürütüldüğü, program değerlendirme sürecini tamamen yansıtmadığı ve bulgularının genellikle yetersiz olduğu sonucuna ulaşılmıştır. Ayrıca yapılan program değerlendirme çalışmalarının da seçilen bir grup tarafından yapııması, alandan çok fazla katılımcının olmaması eğitim programını hazırlayıp değerlendiren uzmanlar ile bu programın asıl uygulayıcıları öğretmenler arasında bir kopukluğa sebep olmakta ve programın değerlendirilmesine engel teşkil etmektedir. Bu durum, mevcut programın ihtiyaçlara doğru cevap verecek şekilde yenilenmesini engellemektedir. Bu bağlamda, alanda çalışan öğretmenlerin mevcut program değerlendirme çalışmalarına ilişkin görüşlerini belirlemenin yanında bu katılımcıların nasıl bir program değerlendirme süreci istediklerini ortaya koymak, ülkemizdeki program değerlendirme çalışmalarının gelişebilmesi adına oldukça önemlidir.

Bu çalışmanın amacı, ülkemizde uygulanan öğretim programlarının en önemli katılımcılarından olan öğretmenlerin mevcut program değerlendirme sürecine ilişkin görüşlerini belirlemek ve bu konudaki önerilerini almaktır. Bu genel amaç doğrultusunda aşağıdaki sorulara yanıt aranmıştır:

- Öğretmenlerin öğretim programlarında yer alan değerlendirme uygulamalarına ve genel olarak programların değerlendirilmesine yönelik görüşleri nelerdir?

- Öğretmenlerin program değerlendirme sürecinde öğretmen, idareci, öğrenci ve velinin rollerine yönelik görüşleri nelerdir?

- Öğretmenlerin program değerlendirme sürecine ve katılımcılarına yönelik önerileri nelerdir?

\section{Yöntem}

\section{Araştırma Modeli}

Araştırma, öğretmenlerin görüşlerini derinlemesine belirlemeye yönelik nitel bir çalışmadır. Bu bağlamda araştırma durum saptamaya yönelik betimsel bir çalışma olup, nitel araştırma teknikleri temel alınarak desenlenmiştir Araştırmada amaç görüş belirleme olduğundan nitel yöntemlerden olan yarı yapılandırılmış görüşme tekniği kullanılmıştır. Bu yaklaşım araştırmacı ve görüşmeciye zaman esnekliği sağlayan, görüşmecinin önceden hazırladığı konu veya alanlara sadık kalarak hem önceden hazırlanmış soruları sorma, hem de bu sorular konusunda daha ayrıntılı bilgiler alma amacıyla ek sorular sorma özgürlüğüne sahip olduğu bir yaklaşım türüdür (Karasar, 2006, s.168; Yıldırım ve Şimşek, 2006, s.122).

\section{Katılımcılar}

Araştırmanın amacı program değerlendirme ve bu süreçteki katılımcı rollerine ilişkin öğretmen görüşlerini belirlemek olduğundan bu konuda ilgili ve istekli olanlara ulaşmak oldukça önem arz etmektedir. Ayrıca program değerlendirme sürecine ilişkin gerekli farkındalığa, bu sürece katkıda bulunabileceği inancına sahip öğretmenlere ulaşmanın daha nitelikli veri sağlayacağı düşünülmüştür. Bu sebepten araştırmada amaçlı örnekleme yöntemlerinden kritik durum örneklemesi ve kartopu örnekleme yöntemi birlikte kullanılmıştır. Bu yöntemlerden kritik durum örneklemesi "bu grup bu problemle karşılaşıyorsa diğer bütün gruplar kesinlikle bu problemle karşı karşıya kalır" şeklinde bir yargının varlığıdır (Patton, 1987; akt: Yıldırım ve Şimşek, 2008).

Kartopu örnekleme yöntemi ise, probleme ilişkin olarak zengin bilgi kaynağı olabilecek birey veya durumların saptanmasında özellikle etkilidir(Yıldırım ve Şimşek, 2008). Programların uygulanması sırasında daha çok problemle karşılaşılan alt sosyo-ekonomik düzeydeki okullarda bulunan öğretmenlerden program değerlendirme konusunda gerekli farkındalığa sahip, ilgili ve istekli olanlara ulaşılmıştır. Bunun için program değerlendirme konusunda farkındalığa sahip olduğu düşünülen eğitim programları ve öğretim alanında lisansüstü öğrenimlerine devam eden ve alt sosyoekonomik düzeydeki okullarda çalışan 2 öğretmenle temasa geçilmiştir. Bu öğretmenlerin de önerisiyle alt SED bölgesindeki ilçede bulunan okullardan kritik olduğu düşünülen 4 okul seçilmiş öğretmenlerle ön görüşmeye gidilmiştir. Daha sonra aralarından program değerlendirme konusunda yeterli olduğunu düşünülen, 
görüşme yapmak isteyenlerle görüşmeler yapılmış ve öğretmenlerin önerileriyle başka okullarda çalışan ve ilgili olduğu düşünülen öğretmenlere ulaşılmıştır. Bu yolla mesleki deneyimi 10 yıl ve üzerinde olan 6 öğretmen ve deneyimi 10 yılın altında olan 5 öğretmen olmak üzere toplam 11 öğretmenle görüşmeler yapılmıştır. Öğretmenlerin eğitim düzeyleri, mesleki deneyimlerine ait detaylar Tablo 1'de sunulmuştur.

Tablo 1.

Öğretmenlerin Kişisel Özellikleri.

\begin{tabular}{llrl}
\hline Öğretmenler & Cinsiyet & Mesleki Deneyim (Yıl) & Eğitim Düzeyi \\
\hline Ö1 & Kadın & 14 & Lisans \\
Ö2 & Kadın & 15 & Lisans \\
Ö3 & 7 & Doktora (Devam ediyor) \\
Ö4 & Kadın & 24 & 2+ Lisans tamamlama \\
Ö5 & Erkek & 2 & Lisans \\
Ö6 & Erkek & 4 & Yüksek Lisans \\
Ö7 & Erkek & 13 & Lisans \\
Ö8 & Kadın & 6 & Yüksek Lisans \\
Ö9 & Erkek & 10 & Lisans \\
Ö10 & Erkek & 8 & Yüksek Lisans \\
Ö11 & Kadın & 12 & Lisans \\
\hline
\end{tabular}

\section{Veri Toplama Aracı}

Çalışmada araştırmacılar tarafından iki bölümden oluşan 12 görüşme sorusu içeren görüşme formu oluşturulmuştur. İlk 6 soru demografik özellikleri, sonraki 6 soru ise öğretmenlerin program değerlendirmeye ilişkin görüşlerini almak üzere hazırlanmıştır. Program değerlendirmeye ilişkin görüş için hazırlanan soruların, araştırmanın amaçlarını yansıtıp yansıtmadığı uzman görüşüne sunulmuş ve biri, Çukurova Üniversitesi Eğitim Fakültesi Eğitim Bilimleri Bölümü’nde Yard. Doç, diğeri aynı bölümde araştırma görevlisi olmak üzere alan uzmanı 2 akademisyen tarafından uygunluğu teyit edilmiştir. Ayrıca dil açısından uygunluk kontrolü de 4 öğretmenle yapılan pilot uygulamada test edilmiş ve gerekli düzeltmeler yapılarak forma son şekli verilmiştir.

Araştırmada kullanılan görüşme soruları araştırma problemleri altında aşağıda sunulmuştur.

- Öğretmenlerin öğretim programlarında yer alan değerlendirme uygulamalarına ve genel olarak programların değerlendirilmesine yönelik görüşleri nelerdir?

o Eğitimde şu anda yapılan program değerlendirmeyi düşündüğünüzde neler söyleyebilirsiniz? Sizce eksik olan nedir?

- Öğretmenlerin program değerlendirme sürecinde öğretmen, idareci, öğrenci ve velinin rollerine yönelik görüşleri nelerdir?

o Eğitim programını hedefleri belirleme, programı geliştirme ve değerlendirme boyutlarıla ele aldığımızda sizce öğretmen, öğrenci, veli ve diğer etkilenenler nerede yer almalı?

- Öğretmenlerin program değerlendirme sürecine ve katılımcılarına yönelik önerileri nelerdir?

o Bir programı değerlendirmeniz istense nasıl bir yol izlerdiniz? Kimler değerlendirme grubunuza katılırdı?

o Bildiğiniz gibi program değerlendirmenin çeşitli türleri mevcut. Bazı yaklaşımlar programın başarısını amaca yaklaşma oranına göre değerlendirmekte iken, bazıları hedef kitlenin ihtiyacına cevabı oranında başarılı olduğunu söylemekte. Sizce bir program değerlendirmede yapılması gereken nedir? 
o Program geliştirme ve değerlendirmede ana odağınıza neleri /kimleri alırdınız? Neden?

o Sizce bir program (sadece okulda yer alan disiplinler değil, hizmet içi eğitim programları, halk eğitim programları, çıraklık eğitim programları, kişisel gelişim programları vs.)uygulama aşamasında da değerlendirilip geliştirilebilir mi? Nasıl?

\section{Verilerin Toplanması}

Bu aşamada öncelikle katılımcılara görüşme hakkında bilgilendirme yapılmış ve yüz yüze görüşme için uygun zaman dilimi belirlenmiştir. Görüşmeler katılımcıların da onayı alınarak ses kayıt cihazıyla kayıt edilmiş daha sonra yazıya dökülerek analize hazır hale getirilmiştir. Bu süreçte her bir görüşme yaklaşık 30 dakika sürmüş ve toplamda 37 sayfalık döküm elde edilmiştir. Daha sonra her katılımcıya görüşmesinin transkripti okutulmuş ve istenen ekleme ve çıkarmalar yapılmıştır.

\section{Verilerin Analizi}

Toplanan veriler betimsel analiz yöntemiyle analiz edilmiştir. Bu aşamada çalışmanın geçerliği ve güvenirliğini sağlamak adına transkriptlerin katılımcılara okutulmasının yanında, ses kayıtları ve raporların uyumu iki araştırmacı tarafından da teyit edilip, betimsel analizdeki bulgular da aynı yöntemle kontrol edilmiştir. Betimsel analizde araştırma soruları temel temaları oluşturmuş ve yanıtlardan öğretmenler Ö1, Ö2... şeklinde kodlanarak uygun alıntılarla desteklenerek sunulmuştur. Bu sayede elde edilen bulgunun hangi yanıtla desteklendiği daha somut hale getirilmeye çalışılmıştır.

\section{Bulgular}

Bu bölümde elde edilen bulgular her bir alt problem altında sunulmuştur.

\section{Birinci Alt Probleme Ait Bulgular}

Araştırmanın birinci alt problemi olan “Öğretmenlerin ilköğretim programındaki değerlendirme uygulamalarına ve bu programın değerlendirilmesine yönelik görüşleri nelerdir?" sorusu yöneltildiğinde üç katılımcı programın değerlendirme uygulamaları açısından yeterli olduğunu dile getirirken; öğretmenlerin büyük çoğunluğu (\%73) programdaki değerlendirme uygulamalarının faydalı olduğunu fakat uygulama aşamasında öğrenci sayısından ötürü zaman sıkıntısı yaşadıklarını dile getirmişlerdir. Ayrıca program değerlendirmenin kapsamında yer alan ölçme değerlendirme alanıyla ilgili değerlendirme uygulamalarında tamamlayıcı yöntemler olan proje ve performans değerlendirmenin toplam değerlendirmedeki ağırlı̆̆ının artması yönünde görüş bildiren iki katılımcı olmuştur. Bu konuda görüş bildiren bir öğretmen "eskisine karşıyım. Bu programda öğrenci daha aktif ve biliyoruz ki kalıcı öğrenme bu şekilde. Sadece değerlendirme kısmında zamandan kaynaklı sıkıntılar yaşıyoruz."(Ö1) şeklinde belirtmiştir. Bu görüşü destekleyen diğer görüşler aşağıdaki gibidir.

Ö2: "programdaki değerlendirme teknikleri oldukça faydalı. Tamam çocuk proje performansla işin içine girip deneyim kazanıyor fakat bunların uygulanabilmesi için sınıflardaki öğrenci sayısı çok fazla, hepsine zaman yetmiyor."

Ö6: "bu noktada kontrol öğretmene kalıyor ve 30-40 kişilik bir sınıfta bu değerlendirmeleri yapmak oldukça zor ve zaman alıcı oluyor."

Mevcut program değerlendirmeye ilişkin görüşler incelendiğinde ise öğretmenlerin hepsinin ülkemizde yapılan program değerlendirmeyi eksik bulduğu ortaya çıkmıştır. Bazı öğretmenler (\%36) yeni programın hiç değerlendirilmediğini düşündüklerini dile getirmişlerdir. Önemli görülen eksikliklerde ilk sırayı programın önemli katılımcılarından olan öğretmenlerin görüşlerinin alınmaması alırken (\%100), ihtiyaç saptamanın yapılmaması (\%36), alandan nitelikli veriler toplanmadan değerlendirmenin yapılması 
(\%55), programla ilgili ortaya çıkan ve bildirilen sorunların dikkate alınmaması gibi eksiklikler dile getirilmiştir. Öğretmenlerden ; "ülkemizde böyle bir değerlendirme yapılmıyor. Neden mi? Bu programı en iyi eleştirecek olan bizlerin görüşleri alınmıyorsa program değerlendirilmiyordur bence."(Ö11), "sağlıklı bir program değerlendirme sürecinin işlediğini düşünmüyorum. Öncelikle değerlendirmeye baz alınacak programın alan uygulama verileri hem süreç hem de nitelik olarak doğru yapılmıyor. Bunlar yetersiz olunca değerlendirme de yetersiz olacaktır."(Ö4) , " programın hedefine ulaşıp ulaşmadığı, kurumlar (MEB, MEM..) sadece çıktıya bakılarak değerlendirilmekte. Geri bildirimler öğretmenlerden istenmemekte ve verilenler de dikkate alınmamakta, bu gayet açı."(Ö6) şeklinde yanıtlar alınmıştır.

\section{İkinci Alt Probleme Ait Bulgular}

Araştırmada İkinci alt problem olan, "Öğretmenlerin program geliştirme ve değerlendirme sürecinde öğretmen, idareci, öğrenci ve velinin rollerine yönelik görüşleri nelerdir?” sorusuna verilen yanıtlar incelendiğinde, öğretmenlerin program geliştirme ve değerlendirme sürecinin her aşamasında aktif olarak yer alması gerektiği tüm katılımcılar tarafından ilk sırada dile getirilmiştir. Bu konuda ; "Kesinlikle öncelik öğretmenin olmalı. Çünkü en gerçekçi kanıtlar onlardan alınabilir. Uygularken karşılaştıkları sıkıntılar, programın neresinin tıkandığı, neresinin hangi gruba uygun olmadığı, hepsinin bilgisini onlardan elde edebilirsiniz."(Ö3) şeklinde görüş bildiren öğretmeni," şu anda olduğu yerde olmamalı. Tersi söyleniyor ama program ne hazırlanırken ne de değerlendirilirken ben öğretmenlerin fikirlerinin alındığını düşünmüyorum. Yani çalışan öğretmenin, bu işin içinde olan öğretmenin fikri alınarak değerlendirme yapılmalı." (Ö2) görüşüyle diğer katılımcı desteklemektedir. Diğer paralel görüşler aşağıdaki gibidir.

Ö5: “...geliştirme ve değerlendirme kısmında mutlaka öncelik öğretmen olmalı. Onların görüşlerine dayalı değerlendirme olmalı. Zaten geliştirme de bu verilere göre yapılmalı."

Ö11:"öğretmenin değerlendirmedeki rolü veri sağlamak ve bu verinin ne anlama geldiğini açıklamak bence. Çünkü işin içinde olan onlar. Sonuçların nedenini de yaşayarak gördükleri için en nitelikli bilgiyi onlardan alabiliriz."

Öğretmenlerin değerlendirme sürecinde idarecileri, kolaylaştırıcı (\%55), işbirliği yapan (\%27), bilgi sağlayan (\%9) ve çok faydası dokunmayan (\%9) olarak gördükleri ortaya çıkmıştır. Bir öğretmen "idare bence bu süreçte kolaylaştırıcı olmalı. Veri toplama sürecini kolaylaştırmalı."(Ö6) şeklinde görüş belirtirken; "idarenin görevi işbirliği yapmaktır. Program değerlendirme sürecinde de kendi okulunda karşılaşılan sorunlar veya durumlar konusunda değerlendirmeyi yapanlarla iletişime geçip işbirliği içerisinde olmalı."(Ö8) ifadesini kullanmıştır.

$\mathrm{Bu}$ süreçte öğrencinin ve velinin rolü sorulduğunda ise ikisinin de aktif katılımı konusunda tüm öğretmenler hemfikirken, büyük çoğunluğu veli ve öğrencinin bilinçsiz olduğunu ve bilinçlendirilme çalışmaları sonucunda katılmaları gerektiğini (\%82) vurgulamıştır. Ayrıca kırsal ve kentsel bölgelerde veliler ve öğrencilerin farklılaşacağı ve kırsal bölgedeki bu gruplar için değerlendirmeye katılımın sıkıntı yaratabileceği de bazı öğretmenler tarafından dile getirilmiştir (\%27).

\section{Üçüncü Alt Probleme Ait Bulgular}

“Öğretmenlerin program değerlendirme sürecine ve katılımcılarına yönelik önerileri nelerdir?” sorusuna yanıtın arandığı üçüncü alt probleme yönelik elde edilen veriler incelendiğinde; öğretmenlerin tamamına yakını ilk sırada programın başarısını ihtiyaca cevap vermesi olarak dile getirirken (\%91), bir öğretmen girdi-işlem- çıktı yaklaşımında(sistem) girdi ve çıktıların uyuşma oranı olarak dile getirmiştir. Bunların yanında öğrencilerin aldıklarının ne kadarını kullanabildiklerini (\%37), günlük hayata aktarma düzeylerini (\%27), bireyin hayatındaki sorunlara ne kadar çözüm olduğunu (\%18) belirleyerek programı değerlendirebileceklerini dile getirmişlerdir. Yanıtlar incelendiğinde; "hedef kitlenin ihtiyacına cevap oluşturup oluşturmadığı başarılı bir programı belirler. Dolayısıyla bir programın hedef kitlesinin ihtiyacını 
karşılaması gerekir."(Ö7) görüşünün yanında; " klasik anlamdaki ülke ihtiyacına cevabın yanında, alınan eğitimin bireyin hayattaki sorunlarına ne ölçüde çözüm olduğuna da bakılmalıdır. Yaşamca anlamlandırılamayan bir eğitim programının mükemmelliği ne ola ki?" (Ö5) yer alırken bir diğer katılımcı "öğrenciye ne kadar faydası olduğuna bakılmalı. Öğrencinin bunları alıp kullanabilmesi çok önemli."(Ö9) ifadesini kullanmıştır.

Ayrıca öğretmenlerin tamamına yakını programın uygulama aşamasında da değerlendirilip geliştirilebileceğini dile getirirken (\%91), bir öğretmen değerlendirmeyi yapacak katılımcıların bu bilince sahip olması koşuluyla bu işlemin yapılabileceğini vurgulamıştır. Bunun yanında öğretmenlerin birçoğu programı uygularken karşılaştıkları sorunlarla ilgili değerlendirme ve geliştirme çalışmalarını informal olarak yaptıklarını dile getirmişlerdir (\%73). Bu noktada öğretmenlerin en önemli sorun olarak dile getirdikleri okullar arası sosyoekonomik düzey farkı tüm yanıtlarda dikkat çekmektedir. Öğretmenlerin tamamına yakınının program geliştirme ve değerlendirme sürecine ilişkin en önemli önerisi programların kırsal, merkez gibi bölgesel farklılıklar dikkate alınarak hazırlanması olmuştur (\%82). Verilen yanıtlar şu şekildedir:

Ö2: "belki de doğrusu bölgesel programlardır. Mesela doğudaki bir sistemle Ankara merkezdeki bir sistemin aynı olması aksaklıklara neden oluyor. Çocukların yaşamları, etkileşimleri farklı, bunlar programa yansıtılırsa çok daha başarılı olur."

Ö6: "biz bunu kendi çapımızda yapıyoruz. Mesela bizim bölgeye uygun olmayan bir etkinliği kendi öğrencimize göre ayarlıyoruz, yeniden oluşturuyoruz. Zaten program çok genel tüm ülkede aynı koşullar varmış gibi hazırlanmış, bu anlamda her bölgede hatta her okulda bu gibi düzeltmeler gerekiyor. Programda bunun en azından kırsal- kentsel bazda yapılması daha iyi olurdu."

Program değerlendirme sürecinin en önemli katılımcısı olarak ise katılımcıların tamamının, öğretmenleri belirttiği tespit edilmiştir. Ayrıca bu süreçte öğretmenlerin büyük çoğunluğu ikinci sırada öğrenciyi (\%82), daha sonra veliyi belirtirken, bazıları veli ve öğrenciyi tek kategoriye alarak ikinci sıraya yerleştirmiştir (\%18). Öğretmenlerin program değerlendirme grubunda olmasını istedikleri gruplar sıklık sırasına göre uzman grubu (\%73), idareciler (\%55), sivil toplum kuruluşları (\%18) olarak ortaya çıkmışıı.

\section{Sonuç, Tartışma ve Öneriler}

Öğretmenlerin mevcut programdaki değerlendirme uygulamalarına ve bu programın değerlendirilmesine yönelik görüşleri incelendiğinde, öğretmenlerin daha çok programın ölçme süreci üzerinde yoğunlaştıkları görülmüştür. Bu paralelde, öğretmenler programda yer alan ölçme değerlendirmeye ilişkin uygulamaları beğendiklerini, fakat zaman yetersizliğinden dolayı uygulama sıkıntıları yaşadıklarını dile getirmişlerdir.

Ülkemizde uygulanmakta olan öğretim programlarının ölçme ve değerlendirme sürecine yönelik olarak yapılan araştırmalar (Acat ve Demir, 2010; Aydın, 2005; Baki ve Bütüner, 2009; Çepni ve Şenel Çoruhlu, 2010; Doğan, Karakaya ve Gelbal, 2007; Gelbal ve Kellecioğlu, 2007; Gözütok, Akgün ve Karacaoğlu, 2005; Şenel Çoruhlu, Er Nas ve Çepni, 2008; Tekışı 2005;) öğretmenlerin programda belirtilen ölçme değerlendirme yöntem ve tekniklerini hazırlama ve kullanma konusunda sorunlar yaşadığını göstermektedir.

Öğretmenlerin ölçme ve değerlendirme uygulamaları konusunda yaşadıkları zaman sıkıntısının bir sebebinin de hazırlama ve kullanabilme konusundaki eksiklik kaynaklı olduğu söylenebilir. Ayrıca, Yücel, Karaman, Batur, Bager ve Karataş'ın (2006) yaptıkları çalışmada, programın uygulanmasındaki engeller arasında bulunan kalabalık sınıflar ve materyal sorunu da bu bulguyla paralellik göstermektedir. Sınıftaki öğrenci sayısı arttıkça öğretimin uygulaması zorlaşmakta ve öğretimin niteliği de düşmektedir. 
Program değerlendirme eğitim ve öğretimle ilgili birçok değişkenin bilimsel olarak incelenmesini gerektiren bir süreçtir. Öğrencilerin başarı ve yeteneklerinin uygun yöntemlerle ölçülüp değerlendirilmesi de programın etkililiğinin belirlenmesi açııından çok önemlidir. Fakat öğretmenlerin farklı ölçme ve değerlendirme yöntemlerini kullanma konusundaki sorunlarının ve sınıfların kalabalık olmasının geçerli bir ölçme ve değerlendirme yapmayı engellediği söylenebilir.

Oliva (1988) program değerlendirmeyi, eğitsel değerlendirme ve öğretimsel değerlendirme şeklinde iki alt boyutta ayırmıştır. Okulla ilgili tüm değişkenleri içine alan eğitsel değerlendirme program değerlendirmeyi ve öğretimsel değerlendirmeyi kapsamaktadır. Öğretimsel değerlendirme ise öğrencinin, öğretmenin ve öğretimde kullanılan yöntemin değerlendirmesini içermektedir. Yukarıdaki öğretmen görüşleri incelendiğinde öğretmenlerin daha çok öğretimsel değerlendirme yapmak eğiliminde oldukları söylenebilir. Diğer taraftan, eğitsel olarak bir programı değerlendirmenin çok boyutluluğu ve öğretmenlerin bu konudaki yeterli veriye ulaşmalarındaki zorluklar dikkate alındığında, öğretmenlerin öğretimin değerlendirmesi üzerinde yoğunlaşmalarının doğal bir eylem olduğu söylenebilir.

Öğretmenlerin ülkemizde mevcut program değerlendirmeyi yetersiz bulduğu ortaya çıkan bir diğer önemli bulgudur. Bu konuda en büyük eksiklik olarak da programın en önemli katılımcılarından olan öğretmenlerin görüşlerinin alınmaması olduğu dile getirilmiştir. Buna bağıı olarak alandan nitelikli veriler toplanmadan, ihtiyaç saptama yeterli oranda yapılmadan doğru değerlendirmenin yapılamayacağı görüşü hakimken, programın hiç değerlendirilmediği düşüncesi de birkaç katılımcı tarafından dile getirilmiştir. Bu doğrultuda öğretmenlerin yapılan program değerlendirmeyi doğru ve yeterli bulmadığı ortaya çıkmaktadır. Bu durum ülkemizdeki programların nitelikli gelişimi konusunda oldukça önemli olan alandan sağlanması gereken verilerin alınmadığı ve kullanılamadığını ortaya çıkarmaktadır. Ülkede uygulanan programların sürekli revize edilmesi hayatidir.

Erden (1998)'in de belirttiği gibi eğitimde program geliştirme programların tasarlanması, uygulanıp değerlendirilmesi ve değerlendirme sonucu elde edilen veriler doğrultusunda yeniden düzenlenmesi sürecidir. Bu noktada değerlendirme sonuçlarının programa yansıtılmasında programın en önemli ve nitelikli katılımcılarında öğretmen dönütleri alınmadığı takdirde yapılan değerlendirme yetersiz olacaktır. Dolayısıyla programa yansıması mümkün olmayacak ve program gerçek dönütlerden yoksun kalarak durağan bir döngüye girecektir.

Ülkemizde programların değerlendirmesi konusunda gerek üniversite, gerekse milli eğitim bakanlı̆̆ı tarafından birçok çalışma yapılmaktadır.2004- 2005 yılında taslak olarak geliştirilen ve aynı öğretim yılında dokuz ilde bulunan 120 İlköğretim okulunda pilot uygulaması yapılan programların değerlendirme çalışmalarını EARGED yürütmüştür (EARGED, 2005). Bu değerlendirme çalışmalarının, geliştirilen programların Türkiye çapında uygulanabilirliğinin denenmesi amacıyla pilot okullarda yapıldığı ve programların uygulanması sürecindeki eksikliklerin, aksayan tarafların, programların güçlü ve zayıf yönlerinin belirlenmesi amacıyla öğretmen, yönetici, müfettiş ve veli görüşlerinin alınması suretiyle daha çok yansıtııı bir değerlendirme niteliğinde olduğu söylenebilir (Özdemir, 2009).

Bunların yanında, deneme uygulamalarının yetersiz olduğu, bir takım eksiklik ve tutarsızlıkları içerdiği, deneme uygulaması süresinin kısa olduğu ve sistematik biçimde yürütülmediği katılımcılardan gelen önemli eleştirilerden olmuştur (Baş Collins, 2005; EPÖ Profesörler Kurulu, 2006; Gözütok, Akgün ve Karacaoğlu, 2005). EPÖ Profesörler Kurulu'nun (2006) da vurguladığı gibi, eğitimde program geliştirme sürecinde deneme uygulamalarının ve bu uygulamalardan elde edilen dönütlerin önemli bir yeri vardır. Çünkü bu uygulamalar sırasında programın işlevselliğinde ve işlerliğinde etkili olan olumsuz etmenler belirlenir ve program taslağında bunları giderici önlemler alınır. Öte yandan deneme uygulamasının yapıldığı örneklem kümesinin tüm evreni temsil edecek nitelikte olması da önemli bir koşuldur (Özdemir, 2009). Ancak, yeni ilköğretim programının deneme uygulaması hem zaman yönünden hem de örneklem yönünden yetersiz olduğu gibi, değerlendirmesinin de çağdaş program geliştirme anlayışında öngörülen biçimde bağımsız ve tarafsız biçimde yapılmaması da önemli bir eksiklik olarak görülmektedir. Ayrıca, yeni ilköğretim programlarının hazırlanmasında, önceki programın uygulayıcılarından ve uygulama sonuçlarından bilimsel bir süreç içinde dönütler alınmadığı 
görülmektedir (Özdemir, 2009). Bu bağlamda programın önemli katılımcılarından öğretmenlerin eleştirileri bu bulgularla paralellik göstermektedir.

Araştırmaya katılan bazı öğretmelerin programların hiç değerlendirilmediğini savunması, öğretmenlerin programların değerlendirilmesi konusunda yeterli düzeyde bilgilendirilmediklerinin bir göstergesi olarak da düşünülebilir. Genel olarak öğretmenler derslerindeki başarının değerlendirilmesi önem veririler. Öğretimin genel olarak değerlendirilmesi ise daha çok okul ya da milli eğitim müdürlükler ve bakanlıktaki yöneticilerin işi olarak görülür. Bu yüzden öğretmenlerin eğitsel değerlendirme konusunda bilgilendirmek ve bu sürece aktif olarak katmak konusunda bazı önlemlerin alınması gerektiği söylenebilir. Öğretmenlerin bu konudaki farkındalıklarının artması, programın değerlendirmesine bütünsel bir bakış açısı getirerek öğretimin verimliliğini de arttırabilir.

Öğretmenlerin program geliştirme ve değerlendirme sürecinde öğretmen, idareci, öğrenci ve velinin rollerine yönelik görüşleri incelendiğinde; öğretmenlerin, öğrencinin ve velinin program geliştirme ve değerlendirme sürecinin her aşamasında aktif olarak yer alması gerektiği konusunda tüm öğretmenler hemfikirken, büyük çoğunluğu veli ve öğrencinin bilinçsiz olduğunu ve bilinçlendirilme çalışmaları sonucunda her iki aşamaya da katılmaları gerektiğini vurgulamıştır. İdarecilerin ise daha çok değerlendirme sürecinde yer alması gerektiği ve "kolaylaştırıcı" görevi üstlenebileceği bulgusuna ulaşılmıştır. Öğretmenlerin mevcut program geliştirme ve değerlendirme çalışmaları konusunda uygulamalardan elde edilen verilerin kullanılması gerektiği vurgusu göz önüne alındığında, öğretmen, öğrenci ve veli katılımcılarının nitelikli veri sağlama rolünü üstlenmelerini istedikleri ortaya çıkmıştır. Ancak veli ve öğrencilerin bu anlamda eksik olduğunun düşünüldüğü gerçeği de bir diğer önemli bulgudur. Bu durumda nitelikli veri sağlamada en önemli katılımcı olarak öğretmen kalmakta, idareci de sürecin işleyişini kolaylaştıran bir kişi olarak düşünülmektedir.

Yukarıda da belirtildiği gibi, araştırmaya kapsamında görüşme yapılan öğretmenler program değerlendirmenin her aşamasında öğretmenlerin bulunmaları gerektiğini vurgulamışlardır. Bunun iki farklı nedeni olabilir. Birincisi öğretmenlerin program değerlendirme konusunda kendilerini merkeze almaları olabilir. İkincisi de programın uygulanması ve öğretimin değerlendirilmesi sürecinde öğretmenin birincil veri kaynağı olarak görülmesinden kaynaklanabilir. Program değerlendirme eğitimin en alt kademesinden en üst kademesine, aşağıdan yukarıya doğru çok boyutlu olarak objektif bilgi akışını gerektirir. Bu yüzden gerekçeleri ne olursa olsun araştırmaya katılan öğretmenlerin program değerlendirme sürecindeki rollerinin öneminin farkında oldukları söylenebilir.

Öğretmenlerin program değerlendirme sürecine ve katılımcılarına yönelik önerileri incelendiğinde; ilk sırada programın başarısının bireylerin ihtiyacına cevap vermesi olarak ele alındığı belirlenmiştir. Bunların yanında öğrencilerin aldıklarının ne kadarını kullanabildiklerini belirleyerek, günlük hayata aktarma düzeylerini belirleyerek, bireyin hayatındaki sorunlara ne kadar çözüm olduğunu belirleyerek programı değerlendirebileceklerini dile getirmişlerdir. Ayrıca öğretmenlerin tamamına yakını programın uygulama aşamasında da değerlendirilip geliştirilebileceğini belirtmişlerdir. Programın en önemli katılımcıları olarak ise öğretmen, öğrenci ve veli belirtilirken, değerlendirme grubu için bunların yanında uzman grubu, idareciler ve sivil toplum kuruluşlarını belirtmişlerdir.

Tüm bu bulgular program değerlendirme yaklaşımları bağlamında incelendiğinde öğretmenler tarafından istenen değerlendirme yaklaşımının; program katılımcılarının programı geliştirme ve değerlendirme sürecinde aktif olduğu, süreçte ortaya çıkan eksikliklerin giderilerek programın dinamik bir yapıda ilerlediği, katılımcıların ihtiyaçlarının karşılanmasına hizmet eden, katılımcı odaklı değerlendirme yaklaşımları kapsamına girdiği görülmektedir. Bunların yanında öğretmenlerin tamamına yakınının program geliştirme ve değerlendirme sürecine ilişkin en önemli önerisi programların kırsal, merkez gibi bölgesel farklılıklar dikkate alınarak hazırlanması olmuştur. Bunun için ise kazanımları aynı fakat sunumu farklı birden çok programın hazırlanması önerisi dile getirilmiştir. 
Bu sonuçlara dayanarak, programın en önemli katılımcılarından olan öğretmenlerin, mevcut program değerlendirme çalışmalarından memnun olmadıklarını ve başta öğretmenler olmak üzere program katılımcılarının daha aktif olduğu, ihtiyaca cevap verme oranını araştıran, uygulama aşamasında değerlendirme ve geliştirme çalışmalarının aktif olarak yapılabildiği bir program değerlendirme yaklaşımına ihtiyaç duyduklarını söylemek mümkündür. Bu doğrultuda;

- Tüm bu istekleri kapsayan katılımcı odaklı değerlendirme yaklaşımlarının ilköğretim düzeyine gerekli çalışmalar yapılarak uyarlanması,

- Okullar arası sosyo-ekonomik farklılıklardan kaynaklı problemlerin azaltılabilmesi için bir program yerine, aynı düzeyde ve aynı kazanımlara yönelik alternatif birkaç programın hazırlanması,

- Okullarda velilerin program değerlendirme sürecine daha aktif katılımlarına ve program değerlendirme konusunda nasıl katkıda bulunabileceklerine yönelik çalışmalar yapılması,

- Öğretmenlerin, program değerlendirme sürecine öğrencileri de dahil etmesi ve öğrenci görüşlerine göre programda düzenlemeler yapması, önerilebilir. 


\title{
Extended Abstract
}

\begin{abstract}
Introduction
As a reflection of learner-centered education widely accepted in today's world, constructivist-based curricula are applied in our country as well. Constructivism is a learning approach which directs the instructional design within stating the aims of the curriculum in relation with higher level thinking skills, deciding on the activities will be used to make the students gain these skills and evaluating it (Biggs, 1996). According to this approach the student's learning ability and success are partially depends on them (Horstman\& White, 2002). One of the fundamental ideas of the constructivist approach is that the students can improve their thoughts with the help of teacher's support and guidance (Warwick and Stephenson, 2002). Therefore, the teacher's leading the student in a right way and his ability to manage the learning-teaching process is significant (Kaptan \& Korkmaz, 2000).
\end{abstract}

In the most general sense curriculum development is designing, applying, evaluating and rearranging the curricula in accordance with the data gathered within the evaluation process (Erden, 1998, p.4). The evaluation an important element of curriculum development process; while specifically is done to determine to what extent the students learn or learning deficiencies and correct them, generally is carried out with the aim of putting forward the applied curriculum's effectiveness or success (Doğan, 1997; Özdemir,2009). According to Tyler (1949), evaluation is the fundamental function of curriculum study and evaluation process is a process of determining the curriculum's objectives and to what extent the expected change on behaviors occurred. Demirel (2006) stated that curriculum evaluation generally contains information by which decision could be made on accepting the education sources based on curriculum, changing or removing them. Briefly, detecting the realization level of intended behaviors, determining the curriculum's deficiencies at the end of application and making the necessary corrections compose the evaluation process (Yaşar, 1998).

Since, development and evaluation of the curriculum are one within another the change in the basic philosophy of the curriculum brings about the change in the evaluation process as well(Marsh and Willis, 2007). One of the biggest criticisms towards traditional evaluation approaches is that evaluation process' carried out without any visit made by the evaluation specialist to the environment where the curriculum is applied. The most noticeable one of the evaluation approaches show up in reaction to this situation is "Participant-Oriented Evaluation Approach". The defenders of this approach consider the participants of the curriculum will be evaluated taking part in the process as significant (Worthern, Sanders and Fitzpatrick, 1997, p.153-154). There are the group the curriculum is applied on, supporters and operator as one of the most important elementsthat is teachers among the participants. During the development of the curriculum, teachers should find a middle way between their own decisions and interests of the learners; so that the process features of constructivism should be revealed (Yurdakul, 2005, p.48).

In our country, when the studies conducted in order to evaluate the primary school curriculum developed in 2005, Gelen and Beyazıt (2007), in their study they carried out with teacher, administrator, inspector and students they analyzed the views on the new and old curriculum, in a way they evaluated this curriculum. Bukova, Güzel and Alkan (2005) evaluated the new primary school curriculum, Çınar, Teyfur and Teyfur (2006) evaluated constructivist education approach and curriculum according to the views of the primary school teachers and administrators. Yücel, Karaman, Batur, Başer and Karataş (2006) and Bümen (2005) aimed to evaluate the primary school curriculum developed in 2005 according to teachers' opinions. Görgen, Karaçelik, Kocatürk, Kapucu and Kaya (2008) evaluated the primary school $1^{\text {st }}-5^{\text {th }}$ grade curricula in regard to primary school teachers' views. 
In addition to this, there are also studies conducted on course basis. Gömleksiz and Bulut (2007) in their study assessed the primary school Turkish curriculum, Arslan and Demirel (2007) evaluated social studies curriculum, İzci, Özden and Tekin (2006) evaluated science and technology curriculum based on teachers' opinions and document analysis. Moreover, there are also studies through which views of teachers, administrators, inspectors, parents and students are received via survey or interview forms in order to evaluate primary school mathematics curriculum (Bal, 2008; Butakın \& Özgen, 2007; Halat, 2007; Orbeyi, 2007; Sarıer, 2007; Uşun \& Karagöz, 2009).

When these studies in the literature are analyzed, even though the studies conducted with teachers it is seen that they are inefficient in terms of serving to deliver teachers' feedback to the curriculum not being able to go beyond taking opinions about the elements of present curriculum, determining the teachers' inadequacies, determining in service training needs.

Evaluation in education starts with the evaluation of the curriculum as the basic element of education. Hence, the flaws and deficiencies of applied curricula should be resolved, curriculum being reorganized in accordance with the changes in the society and science field should be constantly assessed(Yüksel\&Sağlam, 2012). Questioning and assessing how effective the curriculum is the starting point for continuous improvement (Gözütok, 2001). However, the curriculum evaluation field is quite weak in our country (Yaşar, Gültekin, Köse, Girmen \& Anagün, 2005). In our country, apart from the evaluation studies carried out through testing of curricula by Ministry of Education, it is observed that any curriculum evaluation studies were not conducted to evaluate the primary school curricula have been applied since 2005-2006 in a comprehensive and systematic way (Özdemir, 2009). Within the study by Yaşar et. al. (2005)regarding the curriculum evaluation studies in Turkey; the results that the studies mostly focus on only one dimension of curriculum, most of them were carried out by quantitative methods and surveys, they did not fully reflect curriculum evaluation process and findings were generally insufficient were reached. Furthermore, that the curriculum evaluation studies are carried out by a chosen group, not many participants from the field take part in these studies causes disconnection between the specialists preparing and evaluating the curriculum and the real applicators of the curriculum-teachers- and prevents the evaluation of curriculum. This hampers the present curriculum's being renewed to respond to needs in a right way. In this context, it is quite important to put forward what kind of an evaluation process the participants want in terms of curriculum evaluation studies being able to improve.

The purpose of this study to determine the views of teachers as one of the most significant participants of the applied curriculum in our country on present curriculum evaluation process and receive their suggestions for this matter. Within this general purpose, these questions are to be answered:

- What are the teachers' opinions about the evaluation applications taking place in curricula and generally the evaluation of curricula?

- What are the teachers' opinions about the roles of teacher, administrator, student and parents throughout the evaluation process?

- What are the teachers' suggestions for the evaluation process and the participants?

\section{Method}

\section{Research Design}

In this study which is a descriptive study putting forward a situation qualitatively, semi-structured interview method is used. The interview is a technique in which the researcher has the opportunity to ask both the questions prepared beforehand and extra questions in order to get more detailed information about previous questions (Karasar, 2006, p.168; Yıldırım \& Şimşek, 2006, p.122).

Within the research, the critical incident sampling one of the purposive sampling methods and snowball sampling method were used together. The critical incident sampling is the existence of a 
judgment as "if this group is facing this problem all the other groups will also face this same problem" (Patton, 1987; cite in: Yıldırım \& Şimşek, 2008). The snowball sampling method is particularly effective in detecting person or the situation could be rich information source regarding the problem (Yıldırım \& Şimşek, 2008). During the implementation of curricula mostly the concerned and enthusiastic teachers having the necessary awareness for curriculum evaluation working in schools at lower level socioeconomic status were reached out.

\section{Participants}

In the research, 11 teachers were interviewed -6 teachers having 10 years and over experience in the working field and 5 teachers below 10 years' experience.

\section{Instrument}

The interview form developed by the researchers consisting of two parts and 12 questions was used in the study. There are 6 questions in the first part regarding demographic features and another six questions in the second part in order to see teachers' views on curriculum evaluation. The questions prepared for the views on curriculum evaluation were presented to expert opinion in order to determine whether they serve the study's purposes or not and were found appropriate by two domain expert. Furthermore, its suitability in terms of language was also checked during the pilot application with four teachers and the last shape of form was produced making the necessary corrections.

\section{Data Analysis}

The interviews were recorded with the permission of the interviewees and then prepared for analysis being transcribed. Every participant was asked to read transcript of his own interview and the needed additions and extractions were made. Through this study, with the aim of providing the reliability and validity of the study the compatibility of the records with the reports was confirmed by two researchers in addition to participants' reading the transcript, the findings of descriptive analysis were checked using the same method. In descriptive analysis, the research questions formed the basic themes and presented being supported by the suitable quotations from the teachers' answers coding them as $\mathrm{T} 1, \mathrm{~T} 2 \ldots$.

\section{Results}

The findings obtained in this part are presented under each sub-problem.

\section{The Findings for the First Sub-Problem}

For the question "What are the teachers' views regarding the curriculum evaluation applications in primary school curriculum and the evaluation of the curriculum?" while three participants stated that the curriculum is efficient in terms of evaluation applications, most of the teachers (73\%) mentioned that the curriculum evaluation implementations were useful but they suffered from shortage of time during the implementation. Moreover, there were two participants expressing opinion in terms of project and performance evaluation's having a higher proportion in the total evaluation.

All of the teachers found the curriculum evaluation studies in our country insufficient. Some of the teachers (36\%) thought that the new curriculum was not being evaluated at all. While not taking teachers' opinions as the most important participants of curriculum was at the first sequence of the important deficiencies $(100 \%)$, some other deficiencies were also stated such as not conducting needs 
analysis (36\%), making evaluation without collecting qualitative data from the field (55\%), not taking the problems revealed and mentioned related to curriculum into consideration.

\section{The Findings for the Second Sub-Problem}

When the answers to the question "What are the teachers' views regarding the roles of teacher, administrator, student and parent in the curriculum development and evaluation process?" are analyzed, that the teachers should actively take place in every step of curriculum development and evaluation was mentioned by all the participants at first place. It is seen that the teachers thought the administrators as facilitator (55\%), cooperative (27\%), providing information ( $9 \%$ ) and not very helpful (9\%). When the role of student and parent through this process was asked, while all teachers were agreed on the active participation of both, most of them emphasized that the students and parents were ignorant and should participate ( $82 \%$ ) only after they got more knowledgeable. Furthermore, that in suburban and rural areas parents and students would differ and participating in evaluation for these groups in rural area might create a problem was mentioned by some teachers ( $27 \%$ ).

\section{The Findings for the Third Sub-Problem}

When the answers to the question "What are the teachers' suggestions for curriculum evaluation and participants?" were analyzed; while nearly all of the teachers (91\%) stated the success of the curriculum as meeting the need at first place, one of the teachers expressed it as the accordance rate of inputs and outputs in input-output approach. Besides, they mentioned they could evaluate curriculum determining to what extent the students use of what they learned $(37 \%)$, how much they transfer what they learn to everyday life ( $27 \%$ ), how it brings solutions to problems in individual's life (18 \%).

Moreover, while approximately all of the teachers expressed that the curriculum could be developed by being evaluated through the implementation process (91\%), one of them stressed that this could happen only if the participants who would make the evaluation had the necessary awareness. In addition to this, many of the teachers stated that they carried out the evaluation and development practices concerning the problems they encountered through the application of curriculum (73\%).

The most significant recommendation of many of the teachers regarding the curriculum development and evaluation process was preparing the curriculum considering the regional differences such as being in rural or central areas ( $82 \%)$.It is observed that all the participants indicated the teachers as the most important participant of curriculum evaluation process. Additionally, while the majority of the teachers told the students at second place and then the parents in this process (82\%), some thinking student and parent as a single category put them in the second place (18\%).

\section{Discussion, Conclusion \& Implementation}

Teachers said that they liked the applications regarding measurement and evaluation in the curriculum; however, they had problems in practice due to lack of time. The studies conducted related to the measurement and evaluation process of curricula in our country (Acat \& Demir, 2010; Aydın, 2005; Baki \& Bütüner, 2009; Çepni \& Şenel Çoruhlu, 2010; Doğan, Karakaya \& Gelbal, 2007; Gelbal \& Kellecioğlu, 2007; Gözütok, Akgün \& Karacaoğlu, 2005; Şenel Çoruhlu, Ernas \& Çepni, 2008; Tekışık 2005) illustrate that the teachers have problems in terms of preparing and using the measurement and evaluation methods and techniques specified in the curriculum. It can be said that one of the reasons for teachers' having lack of time concerning measurement and evaluation implications is resulted from the inefficiency in preparation and use. Furthermore, in the study that Yücel, Karaman, Batur, Bager and Karataş (2006) conducted crowded classes and material problem which are among the obstacles in the implementation of curriculum also go parallel with this finding. 
Oliva (1988) separated the curriculum evaluation into two sub-dimensions as educational evaluation and instructional evaluation. The educational evaluation including all variables related to school consists of curriculum evaluation and instructional evaluation. Also, the instructional evaluation includes the evaluation of student, teacher and method used for instruction. When the teachers' views above are looked through, it is possible to say that the teachers are mostly intended to make instructional evaluation. On the other side, when the multi-dimensionality of evaluating curriculum educationally and the difficulties that the teachers have trying to get data regarding this matter are considered, it can be said that the teachers' focusing on instructional evaluation is a natural action.

That the teachers find the present curriculum evaluation in our country inefficient is another significant finding. It is mentioned that the biggest deficiency in this matter is not taking teachers' opinions who are the most important participants of curriculum. As Erden (1998) also stated curriculum development in education is rearrangement of curriculum in accordance with the data obtained at the end of evaluation. Therefore, the evaluation and correction without getting feedback from teachers will be inefficient.

In our country, a lot of studies are conducted by either university or ministry of education regarding evaluation of curricula. EARGED carried out the evaluation studies of curricula developed as a draft in 2004- 2005 and pilot scheme of which is done in 120 primary school in 9 cities through the same instructional year (EARGED, 2005). It is probable to say that these evaluation studies are carried out in pilot schools in order to try the applicability of developed curricula in Turkey and have much more the characteristics of a reflective assessment by means of taking opinions of teachers, administrators, inspectors and parents with the aim of determining deficiencies, troubles, strengthens and weaknesses of curricula during the implementation process of curricula (Özdemir, 2009).

In addition to this, that the trial applications are insufficient, include some deficiencies and inconsistencies, the duration of trial application is short and not carried out systematically are among the important criticisms from the participants (Baş Collins, 2005; Curriculum and Instruction Board of Professors, 2006; Gözütok, Akgün \& Karacaoğlu, 2005). As Curriculum and Instruction board of professors (2006) also emphasized the trial implementations and the feedback from these implementations have a significant place in the educational development process.

When the views of teachers regarding teacher, administrator, student and parent's roles in curriculum development and evaluation process are analyzed; the emphasis on use of the data obtained from the applications regarding present curriculum development and evaluation studies is taken into account; it came out that teacher, student and parent participants are willing to assume the role of providing qualitative data. However, the fact that it is thought that parents and students are inefficient in this sense is another crucial finding. In this case, the teacher remains as the most important participant in providing qualitative data, the administrator, on the other hand, is thought as the one who facilitates the process.

When the suggestions of teachers regarding curriculum evaluation process and participants were analyzed; it was indicated that the curriculum's success was identified as giving answer to individuals' needs at first place. Besides, they mentioned they could evaluate the curriculum determining to what extent the students use of what they got, how much they transfer what they learned to everyday life, how much they became response to the problems of individual. Furthermore, nearly all the teachers stated that the curriculum could be developed being evaluated in curriculum implementation process. While teacher, student and parent were stated as the most important participants of curriculum, they also indicated specialist group, administrators and civil society organization in addition to these.

Based on these results, it is possible to say that teachers one of the most significant participants of curriculum are not pleased with present curriculum evaluation studies and need a curriculum evaluation approach through which the curriculum participants especially for teachers are more active, search for the rate of meeting the necessities, evaluation and development studies could be carried out actively during the implementation stage. 
Besides, one of the most crucial suggestions that nearly all the teachers concerning curriculum development and evaluation process brought was the preparation of curricula taking the regional differences such as rural, central into account. For this reason, the suggestion related to prepare more than one curricula having the same attainments but the presentation of which is different was pointed out. 


\section{Kaynakça}

Acat, M. B. \& Demir, E. (2010). Illköğretim programlarındaki alternatif değerlendirme yöntemlerinin uygulanmasında karşılaşılan sorunlara ilişkin sınıf öğretmenlerinin görüşleri. Ahmet Keleşoğlu Eğitim Fakültesi Dergisi, 29, 337-356

Arslan, A. \& Demirel, Ö. (2007). İlköğretim 5. sınıf sosyal bilgiler dersi yeni öğretim programının değerlendirilmesi. Milli Eğitim Dergisi, 175, 198-209.

Aydın, F. (2005). Öğretmenlerin alternatif ölçme değerlendirme konusundaki düşünceleri ve uyguladıkları. In H. Kıran (Ed.), XIV. Ulusal Eğitim Bilimleri Kongresi Kitapçı̆̆ı (pp. 775-779). Denizli: Tübitak Yayınları.

Baki, A. \& Bütüner, S. Ö. 2009. Kırsal kesimdeki bir ilköğretim okulunda proje yürütme sürecinden yansımalar. Illköğretim Online, 8(1), 146-158.

Bal, P. (2008). Yeni ilköğretim matematik öğretim programının öğretmen görüşleri açısından değerlendirilmesi. Çukurova Üniversitesi Sosyal Bilimler Dergisi, 17, 53-68.

Baş Collins, A. (2005). İlköğretim Türkçe programları pilot uygulama değerlendirmesi. Yeni ilköğretim Programlarının Değerlendirilmesi Sempozyumu, Eğitimde Yansımalar VIII. Ankara: Sim Matbaası.

Bukova Güzel, E. \& Alkan, H. (2005). Yeniden yapılandırılan ilköğretim programı pilot uygulamasının değerlendirilmesi. Kuram ve Uygulamada Eğitim Bilimleri, 5(2), 385-420.

Butakın, V. \& Özgen, K. (2007). Yeni ilköğretim matematik dersi öğretim programının (4. ve 5. Sınıf) uygulamadaki etkililiğinin değerlendirilmesi, Diyarbakır ilii Örneği. Dicle Üniversitesi Ziya Gökalp Eğitim Fakültesi Dergisi, 8, 82-94.

Bümen, N. T. (2005). Öğretmenlerin yeni ilköğretim 1-5. sınıf programlarıyla ilgili görüşleri ve programı uygulamaya hazırlayıcı bir hizmet içi eğitim çalışması örneği. Ege Eğitim Dergisi, 6(2), 21-57.

Çınar, O.,Teyfur, E. \& Teyfur, M. (2006). Illköğretim okulu öğretmen ve yöneticilerinin yapılandırmacı eğitim yaklaşımı ve programı hakkındaki görüşleri. Inönü Üniversitesi Eğitim Fakültesi Dergisi, 7(11), 47-64.

EARGED. (2005). Temel eğitim destek programı. Öğretim programlarının (ilköğretim 1-5. sınıflar Türkçe, matematik, hayat bilgisi, fen ve teknoloji, sosyal bilgiler) değerlendirme raporu, Ankara. Retrieved November, 18, 2013 from http://earged.meb.gov.tr/earged/subeler/olcme\%5Fdegerlendirme/ dokumanlar/pdf

EPÖ (Eğitim Programları ve Öğretim) Alanı Profesörler Kurulu. (2006). illköğretim 1- 5.sınıflar öğretim programlarını değerlendirme toplantısı (Eskişehir) sonuç bildirgesi. ilköğretim Online, 5(1), 1-8.

Erden, M. (1998). Eğitimde program değerlendirme. Ankara: Anı Yayıncılık.

Çepni, S. \& Şenel Çoruhlu, T. (2010). Alternatif ölçme ve değerlendirme tekniklerine yönelik hazırlanan hizmet içi eğitim kursundan öğretime yansımalar. Pamukkale Üniversitesi Eğitim Fakültesi Dergisi, 28(2), 117-128.

Doğan, N., Karakaya, í. \& Gelbal, S. (2007). İlköğretim öğretmenlerinin ölçme araçlarıyla ilgili yeterlik algıları ve bu araçları kullanma durumları. I. Ulusal ilköğretim Kongresi. Ankara: Hacettepe Üniversitesi.

Gelbal, S. \& Kelecioğlu, H. (2007). Öğretmenlerin ölçme ve değerlendirme yöntemleri hakkındaki yeterlik algıları ve karşılaştıkları sorunlar. Hacettepe Üniversitesi Eğitim Fakültesi Dergisi, 33, 135-145.

Gelen, i. \& Beyazıt, N. (2007). Eski ve yeni ilköğretim programları ile ilgili çeşitli görüşlerin karşılaştırılması. Educational Administration and Practice, 51, 457-476. 
Gömleksiz, M. N. \& Bulut, İ. (2007). Yeni ilköğretim Türkçe dersi öğretim programının uygulamadaki etkililiğinin değerlendirilmesi. Milli Eğitim Dergisi, 175, 161-184.

Görgen, İ.,Karaçelik, S., Kocatürk-Kapucu, N. \& Kaya, İ. (2008). Yeni ilköğretim 1-5 programlarının sınıf öğretmenlerinin görüşlerine göre değerlendirilmesi. Muğla Üniversitesi Sosyal Bilimler Enstitüsü Dergisi, 20, 115-146.

Gözütok, D., Akgün, Ö. E. \& Karacaoğlu, C. (2005). Yeni ilköğretim programlarının uygulanmasına öğretmenlerin hazırlanması. Eğitimde Yansımalar: VIII Yeni Ilköğretim Programlarını Değerlendirme Sempozyumu (pp.17-40). Ankara: Sim Matbaası.

Halat, E. (2007). Yeni ilköğretim matematik program (1-5) ile ilgili sınıf öğretmenlerinin görüşleri. Afyon Kocatepe Üniversitesi Sosyal Bilimler Dergisi, 9, 63-88.

İzci, E., Özden, M. \& Tekin, A. (2006). Yeni ilköğretim fen ve teknoloji dersi öğretim programının değerlendirilmesi (Adıyaman ili örneği). 15. Eğitim Bilimleri Kongresi Kitapçı̆̆ı (pp.12-13). Ankara: Nobel Yayınları.

Marsh, C. J. \& Willis, G. (2007). Curriculum: Alternative approaches, ongoing issues. New Jersey: Pearson Prentice Hall.

Oliva, P. F. (1988). Developing the curriculum. Boston: Scott, Foresman and Company.

Orbeyi, S. (2007). ilköğretim matematik dersi öğretim programının öğretmen görüşlerine dayalı olarak değerlendirilmesi. Unpublished master's thesis, Çanakkale Onsekiz Mart Üniversitesi, Sosyal Bilimler Enstitüsü, Çanakkale.

Özdemir, S. M. (2009). Eğitimde program değerlendirme ve Türkiye'de eğitim programlarını değerlendirme çalışmalarının incelenmesi. Yüzüncü Yıl Üniversitesi Eğitim Fakültesi Dergisi, 4(2), 126149

Sarıer, Y. (2007). Altıncı sınıf matematik öğretmenlerinin matematik dersi öğretim programına ilişkin görüşleri. Unpublished master's thesis, Eskişehir Osmangazi Üniversitesi, Fen Bilimleri Enstitüsü, Eskişehir.

Stake, R. E. (1975). Program evaluation particularly responsive evaluation. Kalamazoo: Western Michigan University Evaluation Center.

Şenel Çoruhlu, T., Er Nas, S. \& Çepni, S. (2008). Fen ve Teknoloji öğretmenleri için alternatif ölçme ve değerlendirme tekniklerine yönelik bir HiE programından yansımalar: Trabzon örneği. Necatibey Eğitim Fakültesi Dergisi, 2(2), 1-22.

Tekışık, H. H. (2005). Yeni ilköğretim programlarının uygulanmasına öğretmenlerin hazırlanması. Eğitimde Yansımalar VIII: Yeni İlköğretim Programlarını Değerlendirme Sempozyumu. Ankara: Tekışık Eğitim Araştırma Geliştirme Vakfı Yayınları.

Worthen, B. R.,Sanders, J. R. \& Fitzpatrick, J. L.(1997). Program evaluation: Alternative approaches and practical guidelines. New York: Longman.

Yaşar, Ş. (1998). Evaluation of educational programmes in Turkey. Aera Annual Meeting Session. CAUSA.

Yurdakul, B. (2010). Yapılandırmacılık. In Ö. Demirel (Ed.), Eğitimde yeni yönelimler (pp. 39-65). Ankara: Pegem Akademi.

Yücel, C., Karaman, M. K., Batur, Z., Başer, A. \& Karataş, A. (2006). Yeni öğretim programına ilişkin öğretmen görüşleri ve programın değerlendirilmesi. 15. Ulusal Eğitim Bilimleri Kongresi Bildiri Kitapçı̆̆ı, 25-26. 
